\title{
DIAGNOSTIC SIGNIFICANCE OF S-100 PROTEIN, VIMENTIN AND HMB-45 MONOCLONAL ANTIBODIES IN SOME ORAL MELANOMAS
}

\author{
Abdelraheem R. Elgendy * and Khaled A. Hussien **
}

\begin{abstract}
The current study was carried out to evaluate and confirm the sensitivity and specificity of S-100 protein, vimentin and HMB-45 immunohistochemical markers in diagnosis of some oral melanomas. Twelve formalin fixed paraffin- embedded specimen of some intra oral melanomas were collected from the archives of the Clinical Pathology Department of the National Cancer Institute, Cairo University, Egypt and the Oral Pathology Department, Faculty of Dental Medicine, Al- Azhar University, Cairo, Egypt between December 2005G and September 2015G. Immunohistochemical application was performed using strept-avidin-biotin peroxidase procedure. The obtained results showed a variable range of positivity of these markers in all studied cases without negative staining. These findings indicated the diagnostic significance of S-100 protein, vimentin and HMB-45 monoclonal antibodies in oral melanomas. Further studies are needed to investigate the role of these markers in metastasis and prognosis of oral melanomas.
\end{abstract}

\section{INTRODUCTION}

Melanomas of the oral mucosa were first described by Weber in $\mathbf{1 8 5 9}$ as an uncommon malignant neoplasm originated from proliferation of melanocyte cells that present in the basal layer of oral epithelium ${ }^{(1)}$. The incidence of oral melanomas (OMs) is much more unusual comprising 2- $8 \%$ of all melanomas ${ }^{(2)}$ and $0.5 \%$ of all malignant neoplasms of the oral cavity ${ }^{(3)}$. Its exact etiology is unknown, although pre-exsiting melanosis was reported before the development of some oral melanomas in up to $50 \%$ of the cases ${ }^{(3,4)}$. Other predisposing factors, such as denture irritation, tobacco, alcohol and formaldehyde exposure ect., can also induce $\mathrm{OM}$ at some intra oral sites ${ }^{(5)}$.

Clinically, the onset of $\mathrm{OM}$ is usually between $40-70$ years of age with an average of 55 years and it is rare before 20 years ${ }^{(6)}$. OM has a slight gender predilection for males than females by ratio $2-1^{(7)}$. The main sites of $\mathrm{OM}$ are the hard palate followed by the maxillary gingiva, comprising $80 \%$ of all cases $(8,9,10)$. Less common locations

\footnotetext{
* Lecturer of Oral Medicine \& Periodontology, Department of Oral Medicine \& Periodontology, Al - Azhar University, Faculty of Dental Medicine, Cairo ,Egypt.

** Assistant Professor of Oral and Dental Pathology, Department of Oral and Dental Pathology, Faculty of Dental Medicine, Al-Azhar University, Assiut, Egypt.
} 
in order of decreasing incidence include buccal mucosa, mandibular gingiva, lips, tongue and floor of mouth ${ }^{(11,12)}$.Although is very uncommon, a case of intraosseous melanoma in the maxillary alveolus was described by Lombardi et al ${ }^{(13)}$.

Two biological subtypes of OM have been described: invasive melanoma and in situ melanoma with unlike growth pattern. A third type called atypical melanocytic proliferation has also been used. Similar to the cutaneous melanoma, OMs are also divided into four types with different clinical manifestations, histopathological features and prognosis, including superficial spreading malignant melanoma (70\%), nodular malignant melanoma (15\%), lentigo malignant melanoma $(10 \%)$ and acral lentiginous melanoma (5\%), as well as a melanotic melanoma (1-2\% $)^{(12,14-16)}$. The clinical characteristics of $\mathrm{OM}$ are variable ranging from macular lesions to a slowly growing nodule with or without ulceration, bleeding and pain ${ }^{(14,15)}$. The color of OM lesions vary from bluish-black to tan-brown or as an a melanotic form. However, the color depends on the source and the depth of the pigment from which the color is derived ${ }^{(16)}$.

The definite diagnosis of OM is always performed according to the histopathological features, which are identical to those of skin melanoma. Atypical proliferating melanocytes are initially present at the epithelial-connective tissue junction and proliferate toward the surface epithelium and laterally along the basal cell layer ${ }^{(17)}$. Melanocytes show variation in nuclear size, shape and staining reaction. When the vertical growth begins, atypical melanocytes of spindle or epithelioid shape can be seen invading the subepithelial connective tissue ${ }^{(14-18)}$.

Oral malignant melanoma has an ability to histopathologically mimic a variety of other malignancies especially the a melanotic type melanoma, leading to some diagnostic difficulties and subsequent improper treatment. In such cases, the application of immunohistochemical markers using $\mathrm{S}-100$ protein, vimentin and Human melanoma black- 45 (HMB-45)monoclonal antibodies are useful for definite diagnosis of $\mathrm{OM}$ and to distinguish it from other malignancies (19-23). These reliable antibodies react with protein expressed by melanoma and don't involve antigens directly linked to melanin formation, making such immunohistochemical analysis effective in distinguishing pigment -poor melanoma from other tumors with similar microscopic appearance (24-27). Staining with these antibodies may also be useful in locating occult tumor cells in tissue sections, adding in evaluating the depth of invasion and detection of $\operatorname{metastasis}^{(28,29)}$.

S-100 gene family is the largest subfamily of calcium binding proteins of EF-hand type. To date, at least 25 distinct members of this subgroup have been described at chromosome locus 1q21 ${ }^{(30)}$. Upon calcium binding, most S-100 proteins undergo a conformational change allowing the protein to interact with the different protein targets, thereby exerting a broad range of intracellular and extracellular functions. Intracellular functions include regulation of calcium homeostasis, cell cycle, cell growth and migration, phosphorylation, cytoskeletal components and regulation of transcriptional factors. While, extracellular S-100 protein act in a cytokine-like manner by binding to cell surface receptors such as the receptor for advanced glycation end products (RAGE) and Toll-like receptors (TLRs) $^{(31)}$.

Concerning the relationship between S-100 protein and different cancers. Nakajima et al., (32), described S-100 protein staining in formalinfixed paraffin-embedded tissue for a large number of tumors and concluded that S-100 protein was a useful diagnostic tool in tumor diagnosis. Some studies indicated that, S-100 protein have a variety of biological events which are closely related to tumorigenesis and cancer progression (33-35). Other investigators used S-100 protein as a major 
parameter in differentiation of many non-neural crest-derived tumors including Ewing sarcoma, rhabdomyosarcoma and synovial sarcoma ${ }^{(36-39)}$.

Vimentin, a major constituent of the intermediate filament (IF) family of proteins, is universally expressed in normal mesenchymal cells and is known to maintain cellular integrity and provide resistance against stress ${ }^{(40,41)}$. Increased vimentin expression has been reported in various epithelial cancers, including prostate cancer, gastrointestinal tumors, CNS tumors, breast cancer, malignant melanoma, lung cancer and other types of cancers ${ }^{(42-45)}$. Vimentin's over-expression in cancer correlates well with increased tumor growth, invasion, progression and poor prognosis. Extensive review of literatures revealed a few studies dealing with the immunohistochemical expression of vimentin in oral malignant melanoma ${ }^{(46-49)}$. They indicated a future significance of vimentin as a biomarker for OM, with clinical and diagnostic importance $^{(47,48)}$. Recently, vimentin has gained much importance as a marker for epithelialmesenchymal transition (EMT) ${ }^{(50)}$. Although EMT is associated with a number of tumorigenic events, the role of vimentin in the underlying events mediating these processes remains unknown.

Human melanoma black- 45(HMB-45), was discovered by Drs. Allen M. Gown and Arthur M. Vogel in 1986G as a monoclonal antibody that reacts with an intracellular antigen in a variable number of cells in approximately $90 \%$ of melanomas. The specific antigen recognized by HMB-45. It reacts positively against melanocytic tumors but no other tumors, thus demonstrating its sensitivity and specificity ${ }^{(51)}$. Some workers determined the diagnostic usefulness of specific antibodies for proper diagnosis of cutaneous and oral melanomas. They reported that, HMB-45 had 92\% sensitivity when used to identify oral melanoma ${ }^{(51-54)}$. Another report stated that, although HMB-45 is highly specific for identification of OM, some junctional and intradermal nevi may also be reactive ${ }^{(55)}$.
The aim of the present study was to evaluate and confirm the sensitivity and specificity of S-100 protein, vimentin and HMB-45 immunohistochemical markers in accurate diagnosis of oral malignant melanoma.

\section{MATERIALS AND METHODS}

\section{Cases and Tissue Samples:}

Twelve neutral - buffered formalin fixed paraffinembedded tissue specimen of oral melanomas of some intra oral sites, included maxillary gingiva (4/12), anterior palatal mucosa (3/12), posterior palatal mucosa $(2 / 12)$ posterior buccal mucosa $(1 / 12)$, retromolar area (1/12), lower lip (1/12) and tongue (1/12), these paraffin blocks were retrieved from the archives of the Clinical Pathology Department of the National Cancer Institute, Cairo University, Egypt and the Oral Pathology Department, Faculty of Dental Medicine, Al- Azhar University, Cairo, Egypt between December 2005G and September $2015 \mathrm{G}$. The clinical data of all cases at the time of diagnosis, including age, sex, site of involvement and characters were obtained from the medical records. Eight patients were males and four patients were females in a ratio of $2: 1$, ranging in age from $35-65$ years with a mean of 40 years.

\section{Light Microscopical and Immunohistochemical analyses:}

New sections were cut at 5 micron $(\mu \mathrm{m})$ thick from the paraffin wax blocks and stained with haematoxylin and eosin (H\&E) for routine histopathological examination and confirmation of diagnosis. Other section $4 \mu \mathrm{m}$ thick were taken from the specimen blocks and processed for immunohistochemistry using a standard strept-avidin-biotin peroxidase procedure (56), and monoclonal antibodies, including-100 protein, vimentin and HMB-45 at a dilution of 1:100. The chromgen substrate for development of the peroxidase activity was 3,3 diaminobenzidine (DAB). 
The universal kit, the monoclonal antibodies and the chromogen were purchased from DAKO, Glostrup, Denmark. Sections were counterstained with Mayer's haemotoxylin, dehydrated and cover slipped with a permanent mounting medium. To evaluate immunohistochemical staining, at least 10 high -power fields throughout the tumor sections were examined in each case. Immunoreactivity was considered positive if greater than $10 \%$ of the tumor population exhibited cytoplasmic staining and was graded according to the percentage of stained tumor cells as weak (10\%-25\%), mild (26\%-50\%), moderate (51\%-75) and strong (76\%-100\%). Evaluation of the immunohistochemical findings was interpreted independently by consensus of all authors. Discrepancies in grading were resolved by simultaneous review by all investigators.

Statistical analysis of the obtained data was performed by using the Chi-square test to estimate and confirm the predictive or significant value of each marker in proper diagnosis of OMs.

\section{RESULTS}

This study was performed on 12 diagnostic biopsy materials of oral melanoma of different intraoral sites. There were eight men and four women patients $(\mathrm{M} / \mathrm{F}$ ratio2:1) with an age range from $35-65$ years with a mean of 40 years. The

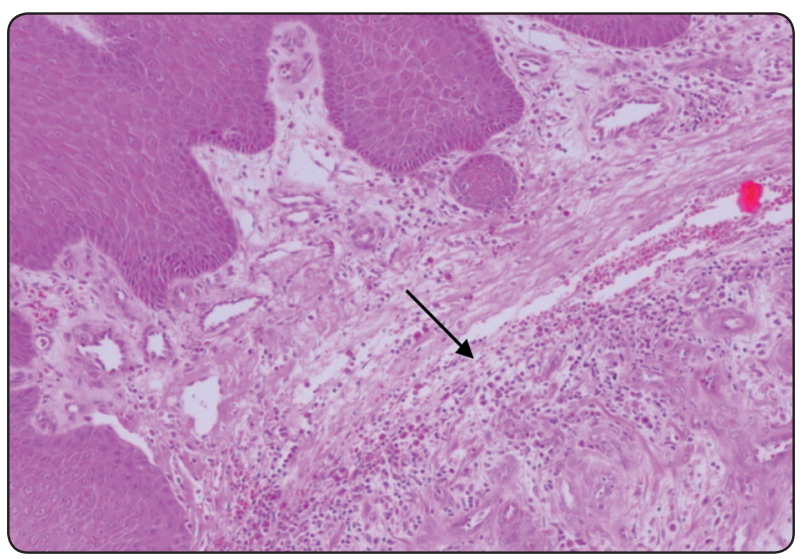

Fig. (1) H \& E staining showing covering epithelium and underlying connective tissue containing sheets of atypical melanocytes with abnormal mitotic figures (X 100). intraoral sites of OM ,included maxillary gingiva (4/12), anterior palatal mucosa (3/12), posterior palatal mucosa $(2 / 12)$ posterior buccal mucosa $(1 / 12)$, retromolar area (1/12), lower lip (1/12) and tongue $(1 / 12)$.

\section{Histopathological and Immunohistochemical findings}

Evaluation of H\&E stained slides in each specimen was independently carried out by all investigation. Agreement was reached on all 12 cases included in this study which showing classic morphologic features of OM similar to that of cutaneous melanomas.

The malignant oral melanoma cells often group in nests or clusters with an organoid fashion, however single cell can predominate. The melanoma cells have large nuclei, often with prominent nucleoli, and show nuclear pseudo-inclusions due to nuclear membrane irregularity. The abundant cytoplasm appeared either uniformly eosinophilic or clear. Occasionally, the cells become spindled or neurotize in some areas. This finding is interpreted as a more aggressive feature, compared with findings of the round or polygonal cell varieties (fig.1\&2).

As far as oral melanomas have a number of histopathologic mimics, including a melanotic type melanoma, poorly differentiated carcinomas and anaplastic large-cell lymphomas leading to

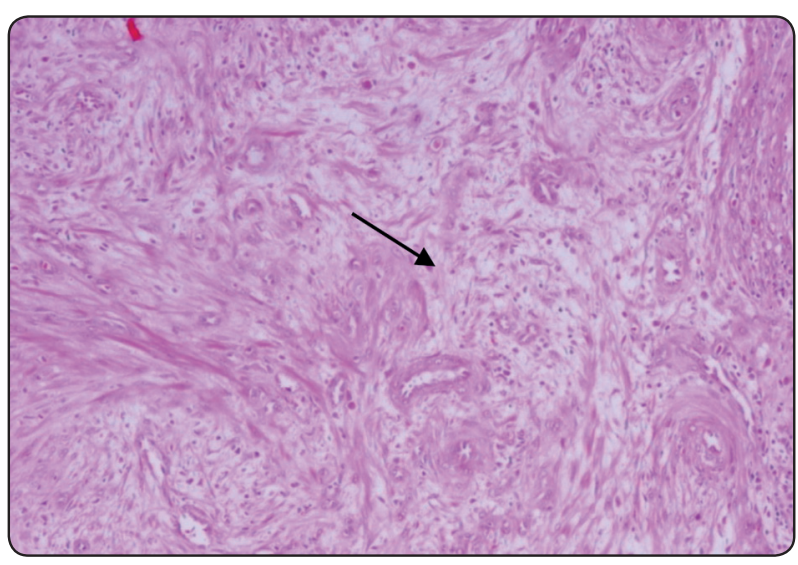

Fig. (2) H \& E staining showing sheets of atypical melanocytes in the underlying connective tissue stroma (X 100). 
misdiagnosis and subsequent improper treatment. Differentiation requires the use of immunohistochemical techniques to highlight intermediate filaments or antigens specific for a particular cell line. In this regard, the immunohistochemical application of S - 100 protein, vimentin and HMB-45 monoclonal antibodies are useful for definite diagnosis of $\mathrm{OM}$ and to distinguish it from other malignancies (19-23).

Immunohistochemical results of all tissue samples of this study are summarized in table 1 . Immunoreactivity was independently assessed by all investigators to reach agreement on all examined cases. S-100 protein expression was obviously evident in 12/12 cases of this study as indicated by presence of mild positive staining in (1/12 cases), moderate positivity in (5/12 cases) or strong positive cytoplasmic membrane localization of the neoplastic melanoma cells in (6/12 cases) (fig.3). Vimentin being a cytoskeletol structural protein, is restricted to the cytoplasmic portion of the cells, but it has been shown to be nuclear as well as an extracellular protein. Immunostaining of vimentin expression in the 12 tissue samples was mild positive cytoplasmic staining in (2/12 cases), moderate positive reactivity in (4/12 cases) and strong positivity in (6/12 cases) of all specimens (fig.4). Also, the expression of HMB-45monoclonal antibody showed characteristic moderate positive cytoplasmic staining in (4/12 cases) and strong cytoplasmic membrane localization in (8/12 cases) of all 12 tissue samples (fig.5).

Statistical analysis of the previously mentioned results of this study, using Chi-square test, indicated that theS-100 protein, vimentin and HMB45 markers were significantly expressed in all studied cases (fig.6).

TABLE (1) immunoreactivity grades of S-100 protein, vimentin and HMB-45 markers in OM.

\begin{tabular}{|l|c|c|c|}
\hline Staining grades & S-100 protein/ No. Cases & Vimentin/ No. Cases & HMB-45 / No. Cases \\
\hline Negative staining & - & - & - \\
\hline Weak staining (10\% to 25\% of cells) & - & - & - \\
\hline Mild staining (26\% to 50\% of cells) & $1 / 12$ & $2 / 12$ & - \\
\hline Moderate staining (51\% to 75\% of cells) & $5 / 12$ & $4 / 12$ & $4 / 12$ \\
\hline Strong staining (76\% to 100\% of cells) & $6 / 12$ & $6 / 12$ & $8 / 12$ \\
\hline
\end{tabular}

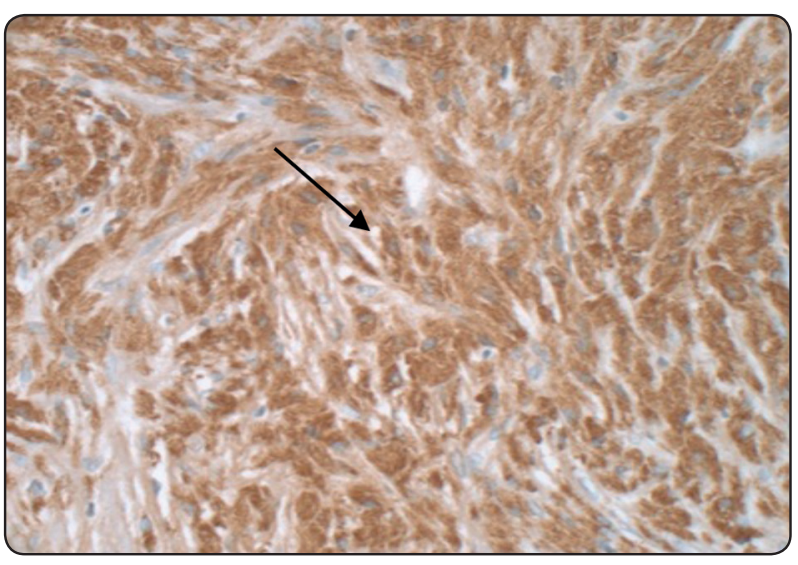

Fig. (3) Immunohistochemical staining of S-100 proteins showing strong positive immunoreactivity of neoplastic melanocytes ( strept- -avidin-biotin tech.,X200).

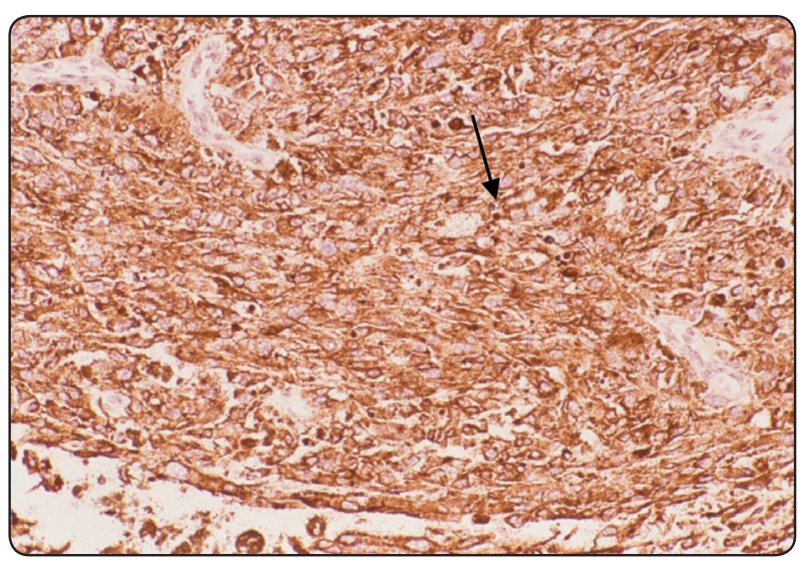

Fig. (4) Strong positive immunohistochemical expression of vimentin throughout the abnormal melanocytes (strept-avidin-biotin tech.,X200). 


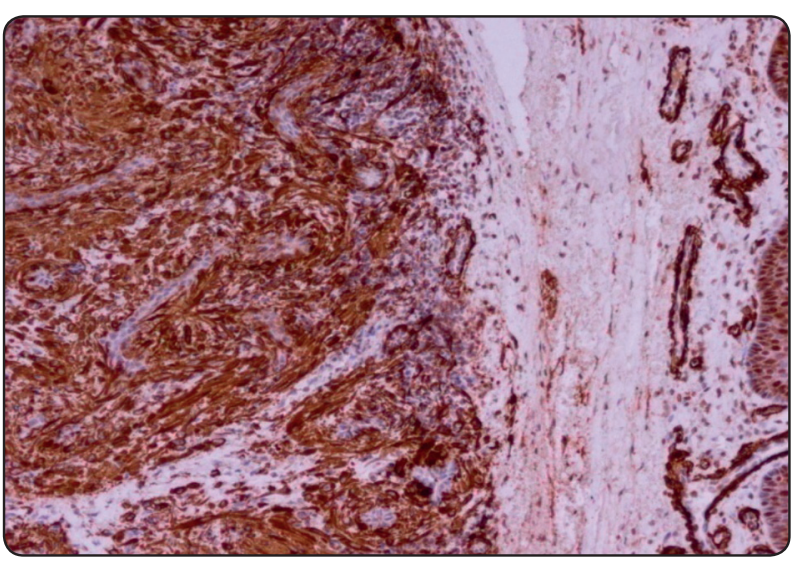

Fig. (5) Immunohistochemical staining of HMB-45showing strong positive sheets of atypical melanocytes ( strept-avidin-biotin tech.,X200).

\section{DISCUSSION}

Oral melanomas are relatively common, and, similar to their cutaneous counterparts, they are thought to arise primarily from melanocytes in the basal layer of the oral squamous mucosa, de novo. Melanocytic density has a regional variation. Facial skin has the greatest number of melanocytes. In the oral mucosa, melanocytes are observed in a ratio of about 1 melanocyte to 10 basal cells ${ }^{(1-3)}$.The onset of $\mathrm{OM}$ is usually between $40-70$ years of age with an average of 55 years and it is rare before 20 years ${ }^{(6)}$. $\mathrm{OM}$ has a slight gender predilection for males than females by ratio $2-1^{(7)}$.

Unlike the incidence of cutaneous melanoma, the prevalence of oral melanoma has remained stable for more than 25 years. In a review of the large studies, melanoma of the oral cavity is reported to account for $0.2-8 \%$ of melanomas and approximately $1.6 \%$ of all malignancies of the head and neck. In some studies, primary lesions of the lip and nasal cavity also are included in the statistics, thereby increasing the incidence. The most common locations of oral mucosa are the palate and maxillary gingiva, in addition to some other intraoral sites ${ }^{(4,5,8-12)}$.

In contrast to cutaneous melanomas, which are etiologically linked to sun exposure, risk factors for

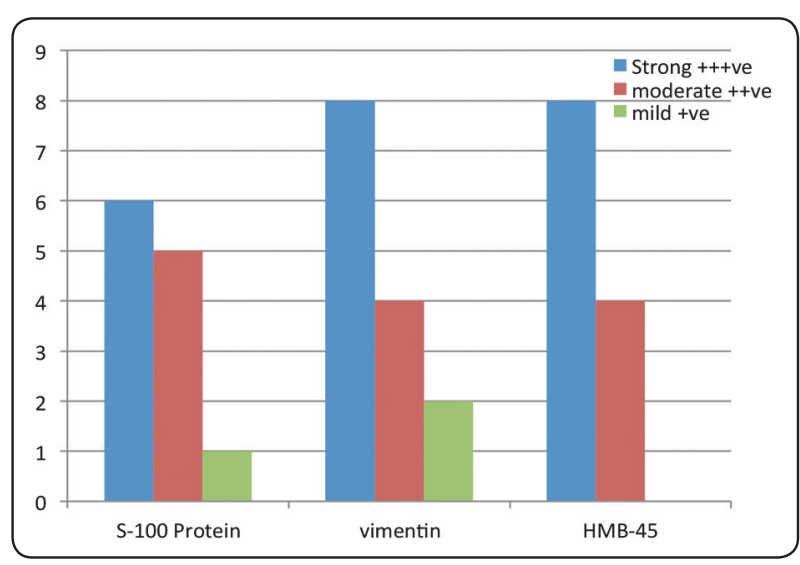

Fig. (6) Diagram showing significance of S-100 protein, vimentin and HMB-45 immunohistochemical markers in diagnosis of $\mathrm{OM}$.

oral mucosal melanomas are unknown. These melanomas have no apparent relationship to chemical, thermal or physical factors (e.g., smoking, alcohol intake, poor oral hygiene, irritation from teeth, dentures or other oral appliances) to which the oral mucosa constantly is exposed. Although benign, intraoral melanocytic proliferations (nevi) occur and are potential sources of some oral melanomas with poorly understood sequence of events ${ }^{(2-4)}$.

Two biological subtypes of OM have been described: invasive melanoma and in situ melanoma. The former type of OM shows an invasive or vertical growth pattern without significant lateral spread. The latter type features a junctional growth phase that may last months to years before entering a with growth pattern. A third type called atypical melanocytic proliferation has also been used vertical growth phase. A third term, atypical melanocytic proliferation, has been used in relation to microscopically difficult oral pigmentations ${ }^{(14-16) \text {. }}$

Similartothecutaneousform,OMsarealsodivided into four types with different clinical manifestations, histopathological features and prognosis, including superficial spreading malignant melanoma (about $70 \%$ ), nodular malignant melanoma (circa 15\%), lentigo malignant melanoma (around 10\% ) and 
acral lentiginous melanoma (approximately 5\%), as well as a melanotic melanoma (round about $1-2 \%)^{(12,14-16) \text {. }}$

Concerning the histopathological results of the present study, all cases are diagnosed as oral melanoma with hematoxylin-eosin staining, which allows easy identification of the disease through its junction activity, diffuse arrangement of spherical or spiny cells with abundant eosinophilic cytoplasm marked by cellular atypia, eosinophilic nucleolus and abundant mitotic figures ${ }^{(2-12)}$.This indicated the importance of hematoxylin - eosin staining in routin diagnosis of all tissue samples before using any special staining ${ }^{(57-60)}$. Noteworthy, Oral melanomas seem uniformly more aggressive and spread and metastasize more rapidly than other oral cancers or cutaneous melanomas. Therefore, early recognition and treatment greatly improves the prognosis ${ }^{(15,17,18)}$.

Immunohistochemistry has been shown to be an effective adjunct to the histopathological diagnosis through the establishment of a definitive diagnosis or through confirmation of hematoxylin and eosin (H\&E) staining. In the present study, the immunohistochemical evaluation of S-100 protein expression in all studied cases revealed mild positive staining in 1/12 cases, moderate positive immunoreactivity in 5/12 cases and strong positive staining in $6 / 12$. This result indicated that $\mathrm{S}-100$ protein is produced by a wide variety of normal and neoplastic cells of protein can be found in the cell membranes, cytoplasm and nuclei of benign and malignant melanocytic tumors. Thus, S-100 protein is considered as a very sensitive marker for malignant melanoma of all types, a negative staining is exceedingly rare $(30-36)$. Consistent with the aforementioned result, many studies ${ }^{(57-61)}$ expressed S-100 protein positivity in more than $90 \%$ of the following neoplasms, such as astrocytoma, glioblastoma, oligodendroglioma, ependymoma and other glial tumors, schwannoma, neurofibroma, benign and malignant melanocytic tumors, granular cell tumor, myoepithelial tumors, polymorphous low grade adenocarcinoma, Langerhans cell histiocytosis, xanthogranuloma, chordoma, and most types of benign and malignant lipomatous tumors.

In the same regard, other investigators ${ }^{(62-64)}$, confirmed the presence of S-100 protein in glial cells, schwann cells and satellite cells, melanocytes, myoepithelial cells, some glandular epithelia (breast, kidney), skeletal and heart muscle cells, fat cells and chondrocytes, and follicular dendritic cells.They explained their observations on the fact that S-100 protein has varying affinity to calcium and other metals. Its properties are related to many basic cell functions such as action diffusion across lipid membranes, microtubule assembly, RNA polymerase activity and plasma membrane function as well as interaction with chromosomes and synaptosomes.

The current study and many researchers interpreted the association between S-100 protein and some cancers through the following observations: firstly, most of S-100 genes are clustered on human chromosome $1 \mathrm{q} 21$, a region prone to genomic rearrangements, supporting that $\mathrm{S}-100$ proteins may be implicated in tumor progression. Secondly, several S-100 members showed altered expression in various malignancies. Finally, a number of S-100 proteins have been shown to interact with and to regulate various proteins involved in cancer and exert different effects on specific target proteins such as p53, and $\beta$-catenin ${ }^{(30-36,60-64) .}$ In conclusion, S-100 protein can be used in differentiation of $\mathrm{OM}$ from other clinically and histopathologically similar lesions particularly sarcomas (e.g., liposarcoma, schwannoma, leiomyoma and gastrointestinal stromal tumor). Although, all authors agreed about the high sensitivity of S -100 protein for all types of cutaneous and oral melanomas,their specificity still low. For this reason, other markers should be included in a panel for proper diagnosis of malignant melanoma, such as HMB-45 and vimentin . 
A large body of evidences realized that, vimentin is a multifunctional protein that potentially regulate different physiological functions, however the true function of vimentin apart from maintaining the structural integrity of the cells is yet to be unraveled ${ }^{(40)}$. Evaluating the expression pattern of vimentin in normal and cancer tissues can be of great value in tumor diagnosis and prognosis. Vimentin over-expression was found in some types of cancers, including cervical cancer ${ }^{(41)}$, renal cell carcinoma ${ }^{(42)}$, certain type of lymphomas (43), papillary thyroid carcinoma ${ }^{(44)}$ and endometrial carcinomas ${ }^{(45)}$. All findings indicated a future significance of vimentin as a biomarker for different malignancies with clinical relevance, more research will be necessary to particularly assess the major function of vimentin in the process of tumorigenesis. Understanding the mechanism of vimentin gene regulation can contribute to the better understanding of cancer and control the invasiveness of the cancer cells. Importantly, expression of vimentin is mainly associated with metastatic phenotype and poor prognosis of the disease outcome. In view of the available data, vimentin expression in oral malignant melanoma still deficient ,but serves as an attractive and a promising diagnostic and prognostic tool.

In this work, immunostaining of vimentin expression in the 12 tissue samples was mild positive cytoplasmic staining in $2 / 12$ samples, moderate positive reactivity in $4 / 12$ cases and strong positivity in 6/12 cases of all specimens. This result is in accordance with that of the previous studies that also demonstrated the sensitivity and specificity of immunohistochemical expression of vimentin, as well as its significant role in definite diagnosis of OM. Taken together, it is evident that vimentin not only serves as a diagnostic tool in the detection of the cancer, but also plays a key role in the development and progression of cancer.

Similar to the obtained immunohistochemical finding of S-100 protein and vimentin, the revealed immunoreactivity of HMB-45 monoclonal antibody was ranged from moderate positive immunoreactivity in $4 / 12$ cases to strong positive staining in $8 / 12$ cases. This finding can be explained on the fact that HMB-45 immunohistochemical marker was highly reactive with the oral melanoma neoplasms for locating occult tumor cells in tissue sections, aiding in evaluation of depth of invasion and detection of metastasis ${ }^{(51)}$. In the same regard, Tanaka et al., ${ }^{(52)}$, have suggested that the biologic behavior of melanoma may be associated with the expression of HMB-45, p53 and p16 proteins, which may be helpful for diagnosis of this neoplasm. Some workers ${ }^{(65-68)}$, claimed that immunhistochemical staining of the HMB-45 marker is mandatory and the basis of the diagnosis of oral malignant melanomas. It have also been proven to be helpful in differential diagnosis and distinguishing melanomas from a variety of poorly differentiated tumors, as well as identification of micrometastases in lymph nodes. According to the previous review there was an agreement with the current finding concerning HMB-45immunhistochemical marker. This observed that the antibody HMB-45 reacts with the melanosomal glycoprotein gp100, showing a positive staining in active early melanosome formation and showing epithelioid lesions intensely immunoreactive for HMB-45. Therefore, it is considered as more specific but less sensitive than the S-100 protein, an acidic calcium binding protein, which is a very sensitive marker for nevus and melanoma cells ${ }^{(54,55,69)}$.

A careful and thorough followed up of any pigmented lesion of the oral cavity is essential to rule out malignant melanoma. In summary, the use of advanced diagnostic method such as immunohistochemistry can definitely aid in earlier identification of oral melanotic lesions, evaluation of the depth of invasion and the detection of micrometastases in lymph nodes as well as prognosis. Further studies are needed in this field to confirm the sensitivity and specificity of S-100 protein, vimentin and HMB-45 immunhistochemical markers in definite diagnosis of oral malignant melanoma of other intraoral sites for proper treatment and prognosis. 


\section{REFERENCES}

1. Weber CO. Chirurgische Ehrfahrungen und untersuchungen, nebst shelreichen beobschtungen aus der chirurgischenklinik und dem evan gelischen krankenhause zun bonn. Berlin: G. Reimer; (1859). p.30-5.

2. James E. Strauss, Sorrell I. Strauss. Oral Malignant Melanoma: A case report and review of literature. J Oral MaxillofacSurg. (1994); 52: 972-6.

3. Gorsky M, Epstein JB. Melanoma arising from the mucosal surfaces of the head and neck. Oral Surg Oral Med Oral Pathol Oral RadiolEndod (1998); 86: 715-9.

4. Soman CS, Sirsat MV. Primary malignant melanoma of the oral cavity in Indians. Oral Surg Oral Med Oral Pathol. (1974); 38: 426-34.

5. Eneroth CM. Malignant melanoma of the oral cavity. Int $\mathbf{J}$ Oral Surg. (1975); 4: 191-7

6. Berthelsen A, Andersen AP, Jensen TS, Hansen HS. Melanomas of the mucosa in the oral cavity and the upper respiratory passages. Cancer. (1984); 154: 907-12.

7. Macintyre DR, Briggs JC. Primary oral malignant melanoma. Int J Oral Surg. (1984); 13: 160-5.

8. Curran JB, Whittaker JS. Primary malignant melanoma of the oral cavity. OralSurg Oral Med Oral Pathol. (1973); 36: 701-6.

9. Bennett AJ, Solomon MP, Jarrett W. Superficial spreading melanoma of the buccal mucosa, report of a case. J Oral Surg. (1974); 34: 358.

10. Sharma BG, Bhurat SK, Chatterji P. Malignant melanoma of the hard palate. ENT J. (1980); 59: 100-4.

11. Rapini RP, Golitz LE, Greer RO Jr, Krekorian EA, Poulson T. Primary malignant melanoma of the oral cavity. A review of 177 cases. Cancer. (1985); 55: 1543-51

12. Gustav RR, DeFiebre BK, Firtell DN. Primary malignant melanoma of the mouth. J Oral Surg (1972); 37: 349.

13. Lombardi T, Haskell R, Morgan PR, Odell EW. An unusual intraosseous melanoma in the maxillary alveolus. Oral Surg Oral Med Oral Pathol Oral RadiolEndod. (1995); 80: 677-82.

14. Regezi JA, Hayward JR, Pickens TN. Superficial melanomas of the oral mucous membranes. Oral Surg Oral Med Oral Pathol. (1978); 45: 730-40.

15. Liversedge RL. Oral malignant melanoma. Br J Surg (1975); 13: 40-55.
16. Clark WH Jr, From L, Bernardino EA, Mihm MC. The histogenesis and biologic behavior of primary human malignant melanomas of the skin. Cancer Res. (1969); 29: 705-27.

17. Gnepp DR. Diagnostic surgical pathology of the head and neck. Philadelphia; WB Saunders Company; (2001):. p. 225-6.

18. Hicks MJ, Flaitz CM. Oral mucosal melanoma: epidemiology and pathology. Oral Oncol. (2000); 36: 152-69.

19. Gazit D, Daniels TE. Oral melanocytic lesions: differences inexpression of HMB-45 and S-100 antigens in round and spindle cells of malignant and benign lesions. J Oral PatholMed, (1994):23: 60-64.

20. Prasad ML, Jungbluth AA, Iversen K, Huvos AG, Busam KJ. Expression of melanocytic differentiation markers inmalignant melanomas of the oral and sinonasal mucosa. Am JSurgPathol, (2001):25: 782-787.

21. Barrett AW, Bennett JH, Speight PM. A clinicopathological and immunohistochemical analysis of primary oral mucosal melanoma. Oral OncolEur J Cancer, (1995):31B: 100-105.

22. Blessing K, Sanders DS, Grant JJ: Comparison of immunohistochemical staining of the novel antibody melan-A with S100 protein and HMB-45 in malignant melanoma and melanoma variants. Histopathology. (1998):32:139_ 146.

23. Orchard GE: Comparison of immunohistochemical labeling of melanocyte differentiation antibodies melanA,tyrosinase and HMB 45 with NKIC3 and S100 protein in the evaluation of benign naevi and malignant melanoma. Histochem J. (2000):32:475-481.

24. Ashfaq R, Weinberg AG, Albores-Saavedra J. Renal angiomyolipoma and HMB-45 reactivity. Cancer (1993), 71(10):3091-97.

25. Clarkson KS, Sturdgess IC, Molyneux AJ. The usefulness of tyrosinase in the immunohistochemical assessment of melanocytic lesions: a comparison of the novel T311 antibody (anti-tyrosinase) with S-100, HMB45, and A103 (anti-melan-A). J ClinPathol. (2001): Mar; 54(3):196-200.

26. Blessing K, Sanders DS, Grant JJ. Comparison of immunohistochemical staining of the novel antibody melan-A with S100 protein and HMB-45 in malignant melanoma and melanoma variants. Histopathology. (1998): Feb; 32(2):139-46. 
27. Friedman HD, Tatum AH. HMB-45-positive malignant lymphoma. A case report with literaure review of aberrant HMB-45 reactivity. Arch Patol Lab Med (1991), 115(8):826-30.

28. Heegaard S, Jensen OA, Prause JU. Comparison of the novel antibody against melan-A with $\mathrm{S} 100$ protein and HMB-45. Melanoma Res. (2000) Aug; 10(4):350-4.

29. Ordonez N, Ji XL, Hickey RC. Comparison of HMB-45 monoclonal antibody and S-100 protein in the immunohistochemical diagnosis of melanoma. Am J ClinPathol, (1988); 90(4):385-90.

30. Heizmann CW, Fritz G and Schafer BW. S100 proteins: structure, functions and pathology. Front Biosci (2002); 7: d1356-1368.

31. Donato R. Intracellular and extracellular roles of S100 proteins. Microsc Res Tech (2003); 60: 540-551.

32. Nakajima T, Watanabe S, Sato Y. S-100 protein in Langerhans cells, interdigitating reticulum cells and histiocytosis X cells. Gann. (1982); 73:429-432.

33. Ning X, Sun S, Zhang K, Liang J, Chuai Y, Li Y and Wang X. S100A6 protein negatively regulates CacyBP/SIPmediated inhibition of gastric cancer cell proliferation and tumorigenesis. PLoS One (2012); 7: e30185.

34. Zhang G, Li M, Jin J, Bai Y and Yang C. Knockdown of S100A4 decreases tumorigenesis and metastasis in osteosarcoma cells by repression of matrix metalloproteinase-9. Asian Pac J Cancer Prev (2011); 12: 2075-2080.

35. Siddique HR, Adhami VM, Parray A, Johnson JJ, Siddiqui IA, Shekhani MT, et al. The S100A4 Oncoprotein Promotes Prostate Tumorigenesis in a Transgenic Mouse Model: Regulating NFkappaB through the RAGE Receptor. Genes Cancer (2013); 4: 224-234.

36. Shimada H, Newton WA Jr, Soule EH. Pathologic features of extraosseous Ewing's sarcoma: a report from the Intergroup Rhabdomyosarcoma Study. Hum Pathol. (1988); 19:442-453.

37. Coindre JM, de MA, Trojani M. Immunohistochemical study of rhabdomyosarcoma. Unexpected staining with S100 protein and cytokeratin. J Pathol. (1988); 155:127-132.

38. Fisher C. Synovial sarcoma. Ann DiagnPathol. (1998); 2:401-421.

39. Fisher C, Schofield JB. S-100 protein positive synovial sarcoma. Histopathology. (1991); 19:375-377.
40. Hesse M, Magin TM, Weber K. Genes for intermediate filament proteins and the draft sequence of the human genome: novel keratin genes and a surprisingly high number of pseudogenes related to keratin genes 8 and 18. J Cell Sci. (2001); 114:2569-75.

41. Fuchs E, Weber K. Intermediate filaments: structure, dynamics, function, and disease. Annu RevBiochem. (1994); 63:345-82.

42. Fuyuhiro Y, Yashiro M, Noda S. Clinical significance of vimentin-positive gastric cancer cells. Anticancer Res. (2010):30:5239-43.

43. Takemura K, Hirayama R, Hirokawa K. Expression of vimentin in gastric cancer: a possible indicator for prognosis . Pathobiology. (1994); 62:149-54.

44. Jin H, Morohashi S, Sato F. Vimentin expression of esophageal squamous cell carcinoma and its aggressive potential for lymph node metastasis. Biomed Res. (2010):31:10512.

45. Hu L, Lau SH, Tzang CH. Association of Vimentin overexpression and hepatocellular carcinoma metastasis. Oncogene. (2004); 23:298-302.

46. Chen YT, Stockert E, Jungbluth A, Tsang S, Coplan KA, Scanlan MJ, et al: Serological analysis of Melan-A (MART-1), a melanocyte-specific protein homogeneously expressed in human melanomas. ProcNatlAcadSci USA. (1996):93:5915-5919.

47. Takahashi K, Isobe T, Ohtsuki Y, Akagi T, Sonobe H, Okuyama T: Immunohistochemical study on the distribution of alpha and beta subunits of S-100 protein in human neoplasm and normal tissues. Virchows Arch B CellPatholInclMolPathol. (1984): 45:385-396.

48. Ramos-Vara JA, Beissenherz ME, Miller MA, Johnson GC, Pace LW Fard A, Kottler SJ: Retrospective study of 338 canine oral melanomas with clinical, histologic, and immunohistochemical review of 129 cases. Vet Pathol, (2000):37, 597-608

49. Hendrix MJ, Seftor EA, Chu YW. Coexpression of vimentin and keratins by human melanoma tumor cells: correlation with invasive and metastatic potential. J Natl Cancer Inst.(1992); 84:165-74.

50. Kokkinos MI, Wafai R, Wong MK, Newgreen DF, Thompson EW, Waltham M. Vimentin and epithelial-mesenchymal transition in human breast cancer--observations in vitro and in vivo. Cells Tissues Organs. (2007); 185:191-203. 
51. Tanaka N, Mimura M, Kimijima Y: Clinical investigation of amelanotic malignant melanoma in the oral region. $\mathrm{J}$ Oral MaxillofacSurg (2004); 62: 933 - 937.

52. Lazarevi'c V, Tiodorovi'c J, Tiodorovi'c-Zivkovii'c D. Immunophenotyping of a melanotic melanoma. A case report. ActaDermatovenerol Alp PanonicaAdriat (2006); 15: $141-143$.

53. Adler MJ, White CR Jr: A melanotic malignant melanoma. SeminCutan Med Surg. (1997); 16: 122 - 130.

54. Gazit D, Daniels TE. Oral melanocytic lesions: differences inexpression of HMB-45 and S-100 antigens in round and spindle cells of malignant and benign lesions. J Oral PatholMed, (1994):23: 60-64,.

55. Yu CH, Chen HH, Liu CM, Jeng YM, Wang JT, Wang YP, et al. HMB-45 may be a more sensitive marker than S-100 or Melan-A for immunohistochemical diagnosis of primary oral and nasal mucosal melanomas. JOral Pathol Med, (2005):34: 540-545.

56. Heras A, Roach CM, Key ME. Enhanced polymer detection system for immunohistochemistry. Lab Invest. (1995);72:165.

57. Godwin A vwioro. Histochemical Uses Of Haematoxylin A Review. JPCS (2011):1:24-34.

58. Lillie RD, Pizzolato P, Donaldson PT Nuclear stains with soluble metachrome mordant lake dyes. The effect of chemical endgroup blocking reactions and the artificial introduction of acid groups into tissues. Histochemistry. (1976) :49: 23-35.

59. Llewellyn BD Nuclear staining with alum-hematoxylin. Biotech. Histochem. (2009):84: 159-177.

60. Puchtler H, Meloan SN, Waldrop FS Application of current chemical concepts to metal-haematein and -brazilein stains. Histochemistry. (1986):85: 353-364.

61. Fan B, Zhang LH, Jia YN, Zhong XY, Liu YQ, Cheng XJ, et al. Presence of S100A9-positive inflammatory cells in cancer tissues correlates with an early stage cancer and a better prognosis in patients with gastric cancer. BMC Cancer (2012); 12: 316.

62. Marenholz I and Heizmann CW. S100A16, a ubiquitously expressed EF-hand protein which is up-regulated in tumors. BiochemBiophys Res Commun (2004); 313: 237-244.

63. Carlsson H, Petersson S and Enerback C. Cluster analysis of $\mathrm{S} 100$ gene expression and genes correlating to psoriasin (S100A7) expression at different stages of breast cancer development. Int J Oncol (2005); 27: 1473-1481.

64. Takahashi K, Isobe T, Ohtsuki Y, Akagi T, Sonobe H,Okuyama T: Immunohistochemical study on the distribution of alpha and beta subunits of S-100 protein inhuman neoplasm and normal tissues. Virchows Arch BCellPatholInclMolPathol. (1984):45:385-396.

65. Messina JL, Glass LF, Cruse CW, Berman C, Ku NK \&Reintgen DS. Pathologic examination of the sentinel lymph node in malignant melanoma. Am J SurgPathol. (1999): 23: 686-690.

66. Blessing K, Sanders DS \& Grant JJ. Comparison of immunohistochemical staining of the novel antibody melan-A with $\mathrm{S} 100$ protein and HMB-45 in malignant melanoma and melanoma variants. Histopathology (1998):32: 139-146.

67. Gazit D \& Daniels TE. Oral melanocytic lesions: differences in expression of HMB-45 and S-100 antigens in round and spindle cells of malignant and benign lesions. $\mathrm{J}$ Oral Pathol Med (1994): 23: 60-64.

68. Kawakami Y, Eliyahu S, Delgado CH, Robbins PF, Rivoltini L, Topalian SL, et al. Cloning of the gene coding for a shared human melanoma antigen recognized by autologous T cells infiltrating into tumor. ProcNatlAcadSci U S A. (1994) : 91: 3515-3519.

69. Barker BF, Carpenter WM, Daniels TE, Kahn MA, Leider AS, Lozada-Nur F, Lynch DP, et al : Oral mucosal melanomas: the WESTOP Banff workshop proceedings. Western Society of Teachers of Oral Pathology. Oral Surg Oral Med Oral Pathol Oral RadiolEndod . (1997) :83: 672-9. 